\title{
TYPES OF EMOTIONAL SELF-REGULATION OF WOMEN WHO HAVE SUFFERED FROM PSYCHOLOGICAL ABUSE IN THE FAMILY
}

\author{
IRYNA KOCHERHINA \\ Ivan Franko National University of Lviv \\ Faculty of Philosophy, Department of Psychology \\ Universytetska Street 1, Lviv, Ukraine \\ E-mail address: irakocherhina@ukr.net
}

\begin{abstract}
Aim. The aim of the paper is to present the results of research on the types of emotional self-regulation of women who have suffered from psychological abuse in family relations.

Methods. 140 Ukrainian women who suffered from psychological abuse in the family were interviewed. For the analysis of the obtained results, methods of statistical processing of data were used.

Results. It has been established that women who were victims of psychological abuse from members of their family may have different types of emotional self-regulation: «Emotionally unstable,» «Adaptive,» «Spontaneous.» It is shown that women with emotionally unstable types of emotional self-regulation are emotionally unstable during psychological abuse in the family, which is manifested in their anxiety, tension, depression, self-criticism. It is said that women who are referred to as having the adaptive type of emotional self-regulation possess a sufficient level of neuropsychic stability and self-control and it has been established that women who are characterized by a spontaneous type of emotional self-regulation, when exposed to psychological abuse, have a low level of self-control, which indicates spontaneity and impulsivity in relationships with others.

Conclusions. Emotional self-regulation does not act as a tool to cancel negative experiences, but it is a change in these experiences for other that helps to optimize their condition. Emotional self-regulation and the ability to manage one's own psychical state for the preservation of mental health are important in the context of psychological abuse in the family. Furthermore, it is emphasised on different types of emotional selfregulation of women in situations of psychological abuse in the family.

Key words: emotional self-regulation, types of emotional self-regulation, psychological abuse.
\end{abstract}

\section{INTRODUCTION}

Due to offences, humiliation, contempt, intimidation, etc. in the current pace of development of public life, increasing sensitivity to human rights is 
becoming an actual aspect of scientific research. Women-related studies in this area are extremely important according to the statistics of psychological services in different countries; on average, every fourth woman who turns to psychologists for help points out that she has been exposed to negative emotional effects or psychological abuse from other people (Tomison, \& Tucci, 1997). Such types of abuse against a woman can be done by partners, parents, friends, colleagues, leaders, etc.. The family, as a specific form of human coexistence, plays an important role in the life of each person. This is an environment that should serve as a source of safety and create conditions for human personality development (Śniegulska, 2016, pp. 101-124). Certainly, the presence of psychological abuse in interactions acts as a stress factor. Therefore, it is necessary to manage one's own mental state for the sake of maintaining mental health, the ability to harmoniously coexist with other people and the outside world and successfully solve life's problems.

Psychological abuse is mostly focused on the emotional sphere of the individual, causing negative emotional experiences, such as self-castigation (Meyer, \& Taylor, 1986, pp. 1226-1234), shame, anxiety (Liebschutz, 1997, pp. 1093-1097), depression, and post-traumatic stress disorder (Campbell, 2002, pp. 1226-1331). Emotional self-regulation does not act as a tool to cancel negative experiences, but it is a change in these experiences with others that helps to optimize their condition. Negative emotions and the feelings of emotional discomfort are objects of emotional self-regulation. The regulation includes control of one's own thoughts, behaviour and experiences. Such areas in aspects of the personality of victims of psychological abuse are poorly researched. The problem of the features of self-regulation of the emotional state of these women remains open.

The concept of regulation was first introduced by P. Janet. He claimed that the ability to self-regulate is the highest criterion for the development of personality. P. Janet considers self-regulation as a process of mediating social norms and values, as a system of internal requirements that transforms a person into an active subject. In the scientific literature, the following types of self-regulation are analysed: personal, volitional, value, motivational, emotional (Koole, 2009, pp. 4-41). Self-regulatory skills are important in building relationships and solving life problems and they gain special significance in the presence of facts of psychological abuse in relations with others, where the regulation of own emotional state is the most important type of self-regulation. Emotional self-regulation is a process of self-control, which includes numerous other processes that control human behaviour. R. Erber and A. Tesser (1992, pp. 339-359) emphasize the importance of cognitive control of the emotional sphere and describe the model of aimful emotional self-regulation, M. Chen and J. Bargh (1999, pp. 215-224) describe the idea of emotional self-regulation through satisfaction of hedonistic needs and propose a model of emotional self-regulation which is oriented on values. S. Koole (2009, pp. 4-41), however, supposes that self-regulation of emotions is coordinated by the integration of the necessary subsystems and processes to maintain a 
chosen direction of actions and describes it through a person-oriented model of emotional self-regulation.

The number of publications concerning the abuse within family is gradually increasing. At the end of the last century, psychological abuse was a part of domestic, physical, sexual violence or other forms of ill-treatment (Arias, \& Pape, 1999, pp. 55-67). Nowadays, psychological abuse is considered to be a special form of ill-treatment which can exist separately from other forms of violence in interactions. Much research has been done on the personal characteristics of women who have suffered from domestic violence; the studies focus on the formation of specific features of a maladaptive woman who is exposed to such violence (Shafe, 1996, pp. 43-51). A description of the consequences of psychological abuse is found in the research of A. M. Tomison and J. Tucci. Also, the researchers investigated diagnostic criteria of psychological abuse, its indications and forms (Sonkin, 2014). Psychological abuse can be a component of domestic violence, but it can also be manifested independently. Therefore, the purpose of this study is to identify the specifics of self-regulation in the emotional sphere of women who have experienced psychological abuse, not only in relations with a partner, but also from parents, siblings, husbands, children, and also describe their types of emotional self-regulation.

\section{RESEARCH OF THE EMOTIONAL SELF-REGULATION OF WOMEN, WHO HAVE SUFFERED FROM PSYCHOLOGICAL ABUSE IN THE FAMILY}

To achieve the goal, we interviewed 140 Ukrainian women who suffered from psychological abuse in the family, aged from 19 to 58 . To study the features of emotional self-regulation, the following methods were used: a questionnaire for revealing the expressiveness of self-control in the emotional sphere, activity and behaviour H. S. Nikiforov, questionnaire Model of Emotional Intelligence M. O. Manoylova, test Emotional barriers in interpersonal communication V. Boyko, the scale Emotional stability-emotional instability of the five-factor questionnaire of personality H. Tsui in adaptation A. Khromov, multi-level personal questionnaire Adaptability A. H. Maklakov and S. V. Chermyanina, test questionnaire Investigation of voluntary self-regulation A. V. Zverkov and E. V. Eidman. For the definition of psychological abuse in family relationships, we used the author's Questionnaire for investigation of psychological abuse against women in the family (Kocherhina, 2017, pp. 82-93), which makes it possible to identify such forms as forbiddance and compulsion, threats, control, contempt, negative evaluation of mental abilities and emotional neglect from father, mother, siblings, older generation (grandparents and grandmothers), husband, his family and children. Respondents were required to indicate the frequency of described phenomena of psychological abuse, evaluating each member of their families. 
We analysed the statistical indicators of cluster analysis (using methods of constructing a hierarchical tree of clustering and K-mean analysis) to identify psychological features of emotional self-regulation in women who suffered from psychological abuse in family relationships. The test allowed us to distinguish three subgroups of respondents, based on the level of indicators of emotional self-regulation (Fig. 1).

The first cluster included $32.1 \%$ of respondents, the second cluster $31.5 \%$ of the women, and the third $36.4 \%$.

Figure 1. The division of respondent women into three subgroups, depending on the level of indicators of emotional self-regulation

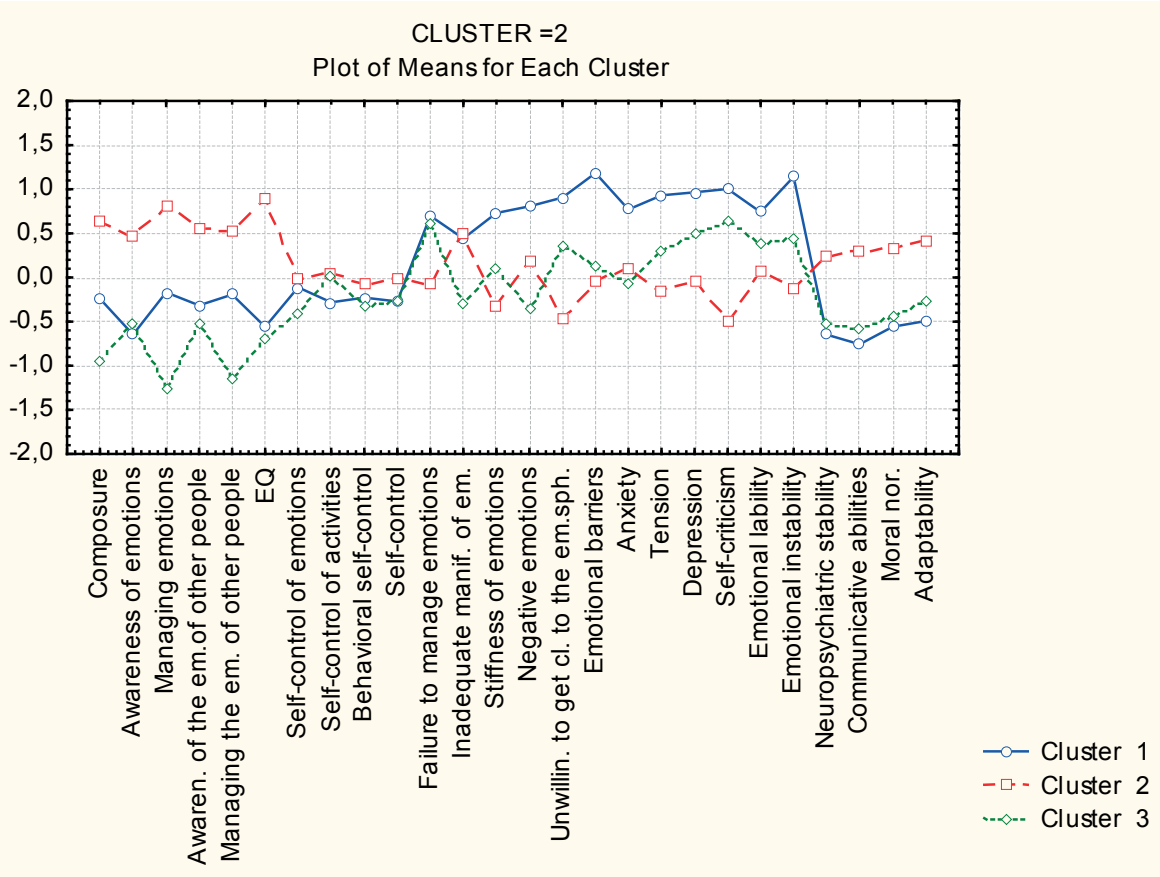

On the basis of this division, we carried out comparative analysis of group scores according to the Scheffé Test. As a result, we found statistically significant differences in the psychological parameters of emotional self-regulation in women exposed to the negative influence of psychological abuse. We have also carried out a correlation analysis of the relationships between the indicators of emotional self-regulation and psychological abuse in the family . 


\section{COMPARISON OF THE COMPONENTS OF EMOTIONAL SELF-REGULATION OF WOMEN VICTIMS OF PSYCHOLOGICAL ABUSE IN THE FAMILY}

Investigated women have different levels of self-control $(p=0.000)$. Such a construct of emotional self-regulation is a volitional aspect and it reflects the level of control of emotional reactions and states. Women who have been included in cluster 2 have the highest level of self-control. Such persons, in the situation of psychological abuse in the family are most emotionally stable, they have internal calm, self-confidence, etc. (Fig. 2).

Figure 2. Indicators of self-control of women with different types of emotional self-regulation in the context of psychological abuse in the family

composure

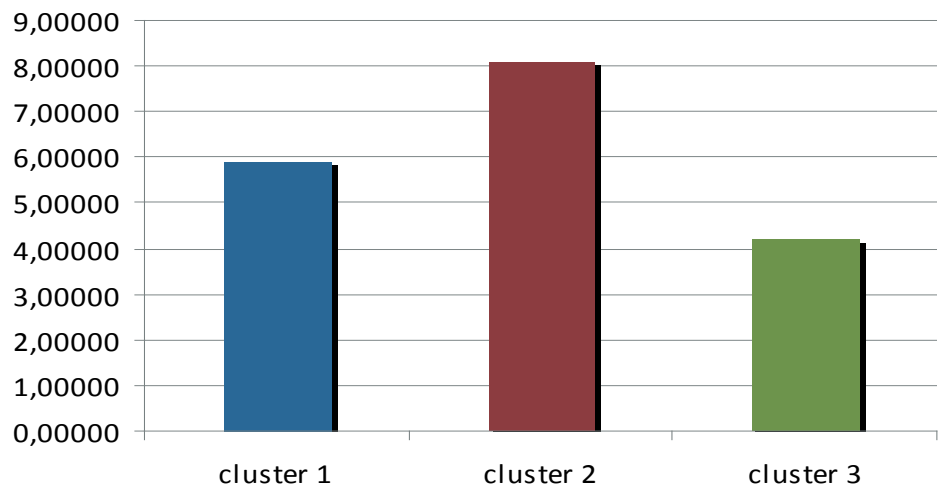

Emotional intelligence, as one of the constructs of emotional self-regulation, performs a regulatory function, plays a role in an adequate external manifestation of emotions and promotes the state of emotional comfort. In the investigated group of women we found statistically significant differences in the indicators of emotional intelligence. Thus, the second cluster included respondents who are characterised by the highest level of ability to realise their emotions and emotions of others in comparison with other clusters, as well as the high level of ability to manage their own emotions and emotions of people around them $(p=0.000)$. In general, their level of emotional intelligence is high.

Data in Figure 3 show that women in the third cluster are characterised by low values for all indicators of emotional intelligence. To sum up, they possess low ability to realise the role of their own feelings and emotions of others, as well as the low level of ability to manage emotions, both their own and others, which reveals their unnecessary needs for self-knowledge and a low level of reflection and understanding of thoughts and feelings of another person. 
Figure 3. Indicators of emotional intelligence of women with different types of emotional self-regulation in the context of psychological abuse in the family

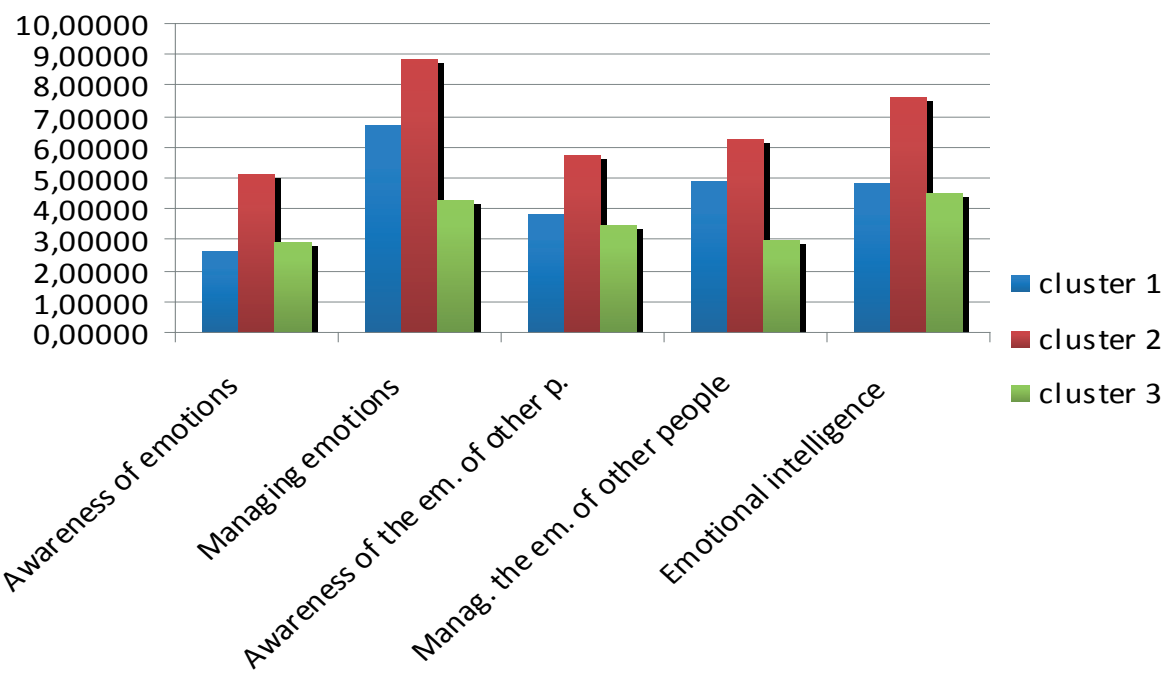

However, the lowest index of emotional intelligence as an awareness of one's emotions is characteristic for women who were included in cluster 1. They also have a low level of ability to orientate in the emotions of communication partner. However, compared to women who joined the cluster 3, they are somewhat higher in such indicators of emotional intelligence as the ability to manage their own emotional state and influence the experiences of others.

Correlation analysis in the second cluster of the researchers revealed the presence of a connection between psychological abuse on the part of the father and emotional intelligence $(\mathrm{r}=0.35)$. That is, we can say that such facts on the part of the father as excessive control, emotional rejection and neglect are related to the awareness of their emotions, understanding their emotional states and their ability to manage them.

Such a construct of emotional self-regulation as emotional stability was studied using indicators of anxiety, tension, depression, self-criticism and emotional stability. Emotional stability as a positive psychological quality of a person is expressed in the fact that emotion in critical moments reaches the optimal intensity, aimed at solving tasks. 
Figure 4. Indices of emotional stability of women with different types of emotional self-regulation in psychological abuse in the family

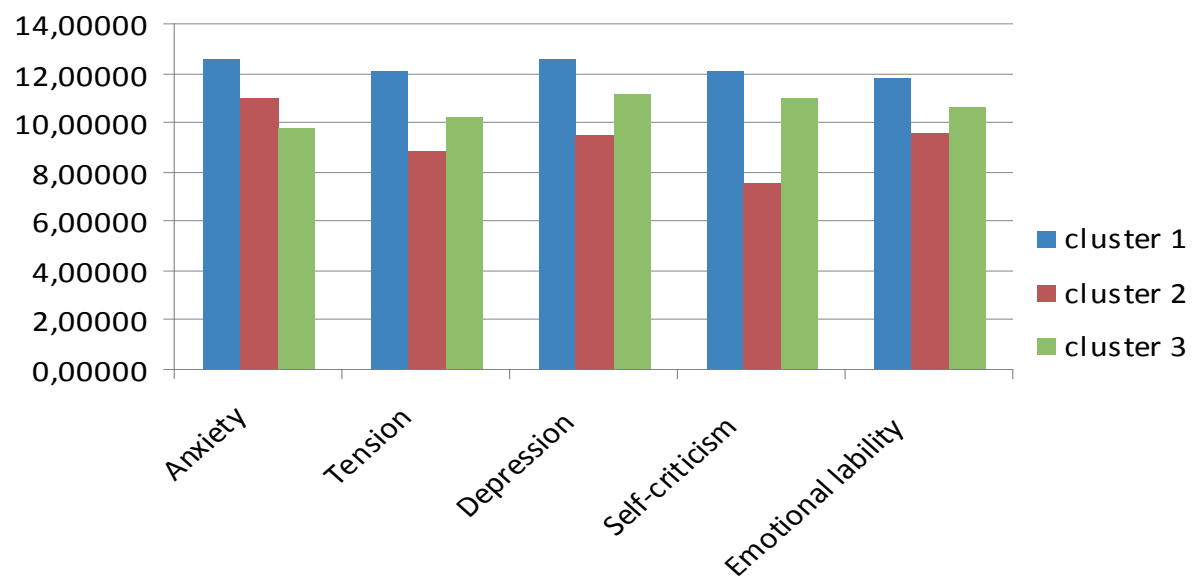

As we can see from Figure 4, women of the second cluster are characterised by average indicators of emotional stability $(p=0.000)$. That is, in comparison with other women who have experienced psychological abuse, in terms of the levels of self-control and emotional intelligence, the women who belong to the second cluster are somewhat more self-confident and more self-sufficient. The women who entered the first cluster are least emotionally stable. Also, in the first cluster of the subjects, there is a correlation between psychological abuse with tension $(r=0.31)$ and depression $(r=0.32)$ as indicators of emotional instability. This testifies to the difficulties in controlling emotions, the impulsiveness of actions that can be externally manifested in the absence of a sense of responsibility, capriciousness, etc. The presence of emotional barriers in interpersonal relationships is reflected in such indicators as inability to manage emotions, inadequate manifestation of emotions, inflexibility of emotions, domination of negative emotions, and reluctance to get in touch with people in the emotional sphere $(\mathrm{p}=0.000)$.

The average level of emotional barriers is characterised by the subjects who entered the cluster 1 . The women who, according to the clustering procedure, are referred to the second and third emotional self-regulation clusters, are mostly lower in comparison with other indicators of emotional barriers in interpersonal relationships (Fig. 5).

The results of the correlation analysis in the group of the second cluster under investigation indicate an interrelation of inadequate manifestation of emotions with psychological abuse ( $r=0.37)$, namely, with such forms as threats $(\mathrm{r}=0.36)$, control $(\mathrm{r}=0.34)$, negative evaluation of women's mental abilities $(r=0.36)$ and emotional disregard $(r=0.40)$. That is, the presence of such features in family interaction as capture from mental abilities, emotional rejec- 
tion and neglect, excessive control associated with difficulties in the situation appropriate to the manifestation of emotions. The analysis of correlations in the first cluster confirms that psychological abuse in the family is associated with such emotional difficulties of a woman as the inability to manage their emotions $(r=0.30)$ and inflexibility of emotions $(r=0.35)$. That is, the women

Figure 5. Indicators of emotional barriers and adaptability of women with different types of emotional self-regulation with psychological abuse in the family
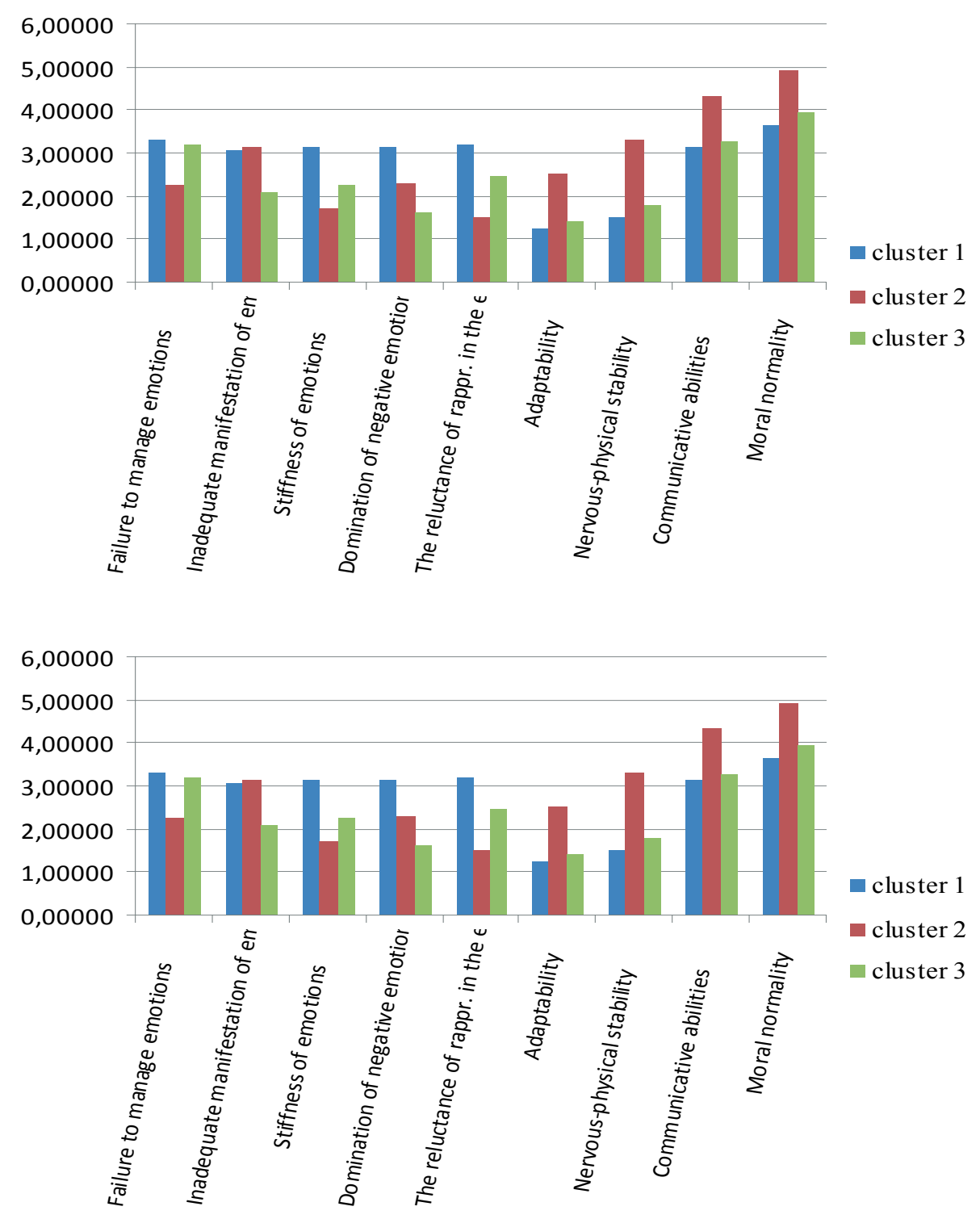
from the first cluster who have a higher level of emotional barriers, in comparison with other groups of women under study, in their family relationships experienced contempt, devaluation of personal qualities and their achievements, emotional rejection, threats.

Adaptability, as a component of emotional self-regulation, suggests emotional stability, ease of adaptation to new external circumstances and the ability to navigate new situations. The women who are assigned to the second cluster have a sufficient level of adaptability (Fig. 5). However, their adaptability is often corrected by the conditions of the environment. Also, the women of this cluster are characterised by a sufficient level of neuropsychic stability, communicative abilities and moral normality, which testifies to their ability to behavioural regulation, adequate self-esteem, and ability to establish contacts with others and adhere to generally accepted norms of behaviour.

The rates of adaptability in women in the clusters one and three are low. Correlation analysis of the data obtained in the first cluster confirms that there is a correlation between the psychological abuse from the father $(\mathrm{r}=-0.40)$ and the mother $(r=-0.36)$ with the person's adaptive potential of the woman, indicating their dependence on conditions of the environment when exposed to psychological abuse in the family. The third cluster contains correlation relationships of neuropsychic resistance with psychological abuse on the part of the father $(\mathrm{r}=-0.43)$ and the mother $(\mathrm{r}=-0.47)$, indicating the presence of difficulties in behavioural regulation and propensity to neuro-mental disruptions in women whose parents show them verbal aggression, contempt, emotional disregard etc.

\section{DESCRIPTION OF TYPES OF EMOTIONAL SELF-ADJUSTMENT OF WOMEN AFTER PSYCHOLOGICAL APPLICATION IN A FAMILY}

Having empirically studied the peculiarities of emotional self-regulation in women who have experienced psychological abuse in the family, it can be stated that they are different in terms of regulation of emotional state. In the process of statistical processing of the results, three groups of women are distinguished and their types of emotional self-regulation are described within the context of psychological abuse in the family.

Thus, the type of emotional self-regulation of the first subgroup (cluster 1) of the subjects can be conventionally described as "Emotionally unstable." These women are characterized by emotional instability which is manifested through anxiety, tension, depression, self-criticism and emotional well-being, that is, they have difficulty controlling emotions and impulsive reactions. This can lead to a sense of helplessness and inability to cope with life's difficulties. The behaviour of women with this type of emotional self-regulation may depend on the situation; they await troubles with anxiety and in the presence of the facts of psychological abuse they can suffer despair and depres- 
sion. A low level of adaptability is also present as one of the components of emotional stability and so is the ability to cope with changing external circumstances, indicating neuropsychic instability and some conflict. For the group under study, emotional barriers in interpersonal relationships and difficulties in establishing emotional contacts were characteristic. The level of emotional intelligence, the ability to control one's emotions and influence the emotions of others is average. Moreover, women of this type possess a low ability to realise their emotions and emotions of other people and they may have difficulty understanding the role of certain emotions, feelings, experiences during activities and communication.

The second subgroup (cluster 2) of the women under study is described as an "Adaptive" type of emotional self-regulation since their level of emotional intelligence is the highest among the subjects and the rate of adaptability in this subgroup is within the average. That is, the women with an adaptive type of emotional self-regulation are characterised by a sufficiently developed emotional self-awareness. They are prone to reflection of the emotional features of the partner in communication, are able to manage their emotions and feelings and control manifestations thereof, develop self-control and awareness of their own psycho-emotional states at each particular moment and possess an adequate understanding of what is happening around. Also, there is the development of such a component of emotional intelligence as managing their emotions, i.e. a high level of ability to take and control their experiences and feelings is present, which indicates a good awareness of their own psychoemotional state. However, sometimes an inadequate manifestation of emotions may occur, perhaps as a result of certain anxiety and emotional lability. These women have a high self-control rate, reflecting the level of arbitrary control of emotional reactions and conditions. Such a result shows that in spite of psychological abuse from the family members, a sufficient level of neuropsychic stability is maintained. That is, the level of self-ownership in different situations is high. Inner peace is characteristic of them, their self-confidence reduces the level of fear of the unknown and increases their readiness for the perception of the new one.

The third subgroup (cluster 3) of the women under study is characterized by a "Spontaneous" type of emotional self-regulation in psychological abuse, as these women have the lowest level of self-control among the sample, indicating spontaneity and impulsivity in relationships with others. In addition, this group of women is characterised by a low level of awareness of the emotions of both their own and other people. That is, the researched members of this group have a low level of reflection and understanding of thoughts, feelings of another person and often have difficulties understanding the causes of other people's behaviour. Characterised by the low ability to control their emotions and feelings, as well as the emotions of other people, they can be impulsive, and sometimes their emotions can complicate the completion of their tasks. They may also be intolerant to the position, values and lifestyles of other people. For the women of this type there is no installation on the positive, 
optimistic perception of themselves, others, and life as a whole. They have difficulties with empathy and identification with the emotional state of their communication partners. They have a lower level of self-observation, passivity and rigidity of communications, which is confirmed by a low level of adaptability and neuropsychic stability. They have a high level of tension and depression, as well as emotional stability, which affects the reduction of emotional stability. Because of this, they tend to feel worse in stressful situations in which they experience internal tension.

\section{CONCLUSIONS}

We can conclude that psychological abuse as a destructive and dysfunctional model of family relationships has a significant impact on the emotional sphere of women. The investigated women who experienced psychological abuse in family relationships differ in particular in the regulation of emotional states. Therefore, we can say that there are three types of emotional self-regulation of women who have experienced psychological abuse in relationships with members of their families.

The "Emotionally unstable" type of emotional self-regulation of women experiencing psychological abuse in family relationships is described due to their low level of emotional stability, impulsiveness, neuropsychic instability, coupled with low adaptability and the presence of emotional barriers in dealing with their surroundings. There is a correlation between the psychological abuse on the part of parents with the person's adaptive potential of a woman, indicating their dependence on the conditions of the environment in a situation of psychological abuse in the family.

The "Adaptive" type of emotional self-regulation is characteristic of women who, having negative experiences of psychological abuse in the family, maintain a high level of self-control as being able to manage themselves in different situations, understand their emotions and are able to manage them, do not have an excessive amount of emotional barriers in their relationships with others, and are also characterised by adaptability in changing conditions. At the same time, the presence of such features in family interaction as capture of mental abilities, emotional rejection and neglect, excessive control associated with difficulties in the situation appropriate to the manifestation of emotions.

The "Spontaneous" type of emotional self-regulation describes women who are vulnerable and exhibit low emotional stability and adaptability, low level of emotional intelligence and insufficient awareness of all the shades of their own experiences and experiences of other people. The presence of the facts of psychological abuse by the family members who manifest verbal aggression, contempt, emotional neglect, etc. is associated with the difficulties of behavioural regulation, a tendency to neuropsychiatric breakdowns in women. 


\section{REFERENCES}

1. Arata, C. M. (1999). Coping with rape: the roles of prior sexual abuse and attributions of blame. Journal of Interpersonal Violence, 14, 62-78.

2. Arias, J., \& Pape, K. T. (1999). Psychological abuse: Implications for adjustment and commitment to leave violent partners. Violence and Victims, 14, 55-67.

3. Campbell, J. C. (2002). Health consequences of intimate partner violence. Lancet, 35, 1226-1331.

4. Chen, M., \& Bargh, J. A. (1999). Nonconscious avoidance and approach behavioral consequences of the automatic evaluation effect. Personality and Social Psychology, 25, 215-224.

5. Erber, R., \& Tesser, A. (1992). Task effort and the regulation of mood: The absorption. Journal of Experimental Social Psychology, 28, 339-359.

6. Kemp, A., Green, B. L., Hovanitz, C., \& Rawlings, E. I. (1995). Incidence and correlates of posttraumatic stress disorder in battered women. Journal of Interpersonal Violence, 10, 43-55.

7. Kocherhina, I. (2017). Апробація методики дослідження психологічного насильства над жінками в родині [Approbation of the questionnaire for the investigation of psychological abuse against women in the family]. Psychology and Personality, 1(11), 82-93.

8. Koole, S. L. (2009). The psychology of emotion regulation: An integrative review. Cognition and Emotion, 23, 4-41.

9. Liebschutz, J. M. (1997). Victimization among substance-abusing women: worse health outcomes. Archives of Internal Medicine, 157, 1093-1097.

10. Meyer, C. B., \& Taylor, S. E. (1986). Adjustment to rape. Journal of Personality and Social Psychology, 30, 1226-1234.

11. Schaef, A. (Ed.). (1996). Co-dependence: Misunderstood. San Francisco: HarperOne.

12. Sonkin, D. J. (2014). Difining psychological maltreatment in Domestic Violence Perpetration Treatment Programm: Multiple Perspectives. Retrieved from http:// www.daniel-sonkin.com/.

13. Śniegulska, A. (2016). Przemoc wobec kobiet i osób starszych w środowisku rodziny [Violence against women and the elderly in the family environment]. Journal of Modern Science, 4, 101-124.

14. Tomison, A. M., \& Tucci, J. (1997). Emotional Abuse: The Hidden Form of Maltreatment. Retrieved from http://www.aifs.org.au/hch/issues.html. 